\title{
Giant Multiple Bilateral Angiomyolipoma
}

Mohammed R. Aljumaili', Samy M. Arafat', Radhakrishnan Kumaran', Mustafa Y. Rashid Al-badra ${ }^{2}$, Yosr A. Hassan², Ayman Saleh ${ }^{3}$

Department of Urology ${ }^{1}$ and Radiology ${ }^{2}$, Sheikh Khalifa Bin Zayed Hospital, Ajman, UAE; Department of Radiology ${ }^{3}$, Dubai Hospital, Dubai, UAE.

\begin{abstract}
:
Introduction: Angiomyolipoma is a benign renal tumor, possibly derived from epithelioid cells surrounding blood vessels. The tumor consists of multiple vessels, smooth muscle and adipose tissue. Angiomyolipoma constitutes less than $10 \%$ of renal tumors, with autopsy series about $0.3 \%$ and ultrasound screened populations around $0.13 \%$. Angiomyolipoma is more common in females, rare before puberty, suggesting a potential hormonal influence. Case Report: We are reporting a case of multiple, bilateral angiomyolipomas in a young lady with tuberous sclerosis presented for the first time with acute spontaneous retroperitoneal bleeding and hypovolemic shock. CT scan was diagnostic and because of high risk of bleeding, biopsy was not recommended for this case. The mainstay of treatment was selective embolization which provides the nephron-sparing approach necessary to preserve renal function and overall quality of life. Conclusion: Preservation of renal function and overall quality of life are the main target in the management of this urologic dilemma and whether conservative medical treatment followed by intervention is superior to emergency intervention (embolization; open or laparoscopic/robotic partial nephrectomy) remains the sole question to be answered in the future.
\end{abstract}

Key words: Angiomyolipoma, Epithelioid Cells, Kidney Neoplasms, Nephrectomy, Tuberous Sclerosis.

\section{Introduction}

Angiomyolipoma is a rare benign renal tumor consisting of multiple vessels, smooth muscle and adipose tissue. The tumor is initially considered to be a form of hamartoma [1,2]. Angiomyolipoma constitutes less than $10 \%$ of renal tumors, with autopsy series about $0.3 \%$ and ultrasound screened populations around $0.13 \%[3,4]$. Angiomyolipoma is a single asymptomatic tumor commonly seen in middle aged woman, rare before puberty, suggesting a potential hormonal influence $[5,6]$.

Although most often sporadic, it can also be associated with the autosomal dominant tuberous sclerosis complex (TSC). Approximately $50 \%$ of

\section{Corresponding Author: Dr. Mohammed R. Aljumaili}

Email: maljumayli@yahoo.com

Received: February 8, 2016 | Accepted: April 23, 2016 | Published Online: June 5, 2016

This is an Open Access article distributed under the terms of the Creative Commons Attribution License (creativecommons.org/licenses/by/3.0)

Conflict of interest: None declared | Source of funding: Nil | DOl: http://dx.doi.org/10.17659/01.2016.0059 
patients with TSC develop angiomyolipomas, typically young age female with symptomatic tumors $[1,2,7,8]$. Those patients may develop renal cysts and at higher risk of developing RCC and lymphangioleiomyomatosis $[9,10]$. The Wunderlich syndrome, or massive retroperitoneal hemorrhage, representing the most significant complication and was reported in up to $10 \%$ of renal angiomyolipoma $[1,9,11,12]$. Pregnancy appears to increase the risk of bleeding from angiomyolipoma, a factor that can influence clinical decision making [1]. Most tumors are now diagnosed incidentally during radiologic workup of unrelated complaints; angiomyolipoma is confidently diagnosed on cross-sectional imaging $[6,13]$. For optimum management, treatment must be individualized. Joint decision and patient preference were considered crucial for the patient's best interest.

\section{Case Report}

A 36 years old woman, from Palestine, presented in November 2015, with sudden, severe, right side abdominal pain associated with vomiting. She denied history of hematuria, fever and lower urinary tract symptoms. She was married for 5 years with no children and there was no significant past history or family history. On physical examination at time of presentation, the patient looked anxious, pale with extensive dark brown skin pigmentations involving the face in butterfly distribution and trunk, patient was a febrile with tachycardia and hypotension. The abdomen was diffusely distended, tender with bilateral flank mass and no added sounds.

Preliminary blood and urine tests revealed, normocytic-normochromic anemia, borderline renal function with no pyuria or hematuria. Soon after resuscitation with 2 units packed red blood cells and 4 units of plasma expanders, patient was stable and transferred for radiological assessment. Ultrasonography and CT scan revealed massive retroperitoneal hemorrhage; bilateral, multiple angiomyolipoma; right lower pole heterogeneous mass suggestive of RCC; left hydronephrosis [Fig.1,2] and intracranial calcifications (cerebral subepindymal) [Fig.3]. CT - angiography showed three right side aneurismal dilatations (bleeding sites) which confirm the diagnosis and management plan was formalized [Fig.4,5].

The condition, treatment options (conservative versus intervention; open versus embolization), the availability of therapeutic intervention (selective embolization was not available in our health care facility) and future expectations (uremia, dialysis, renal transplant), were explained to the patient and decision was made to carry on conservative treatment followed by elective, selective embolization of the right kidney and reassessment for further management.

\section{Conservative management consisted} of strict bed rest, light diet, intravenous fluids and prophylactic antibiotic of third generation

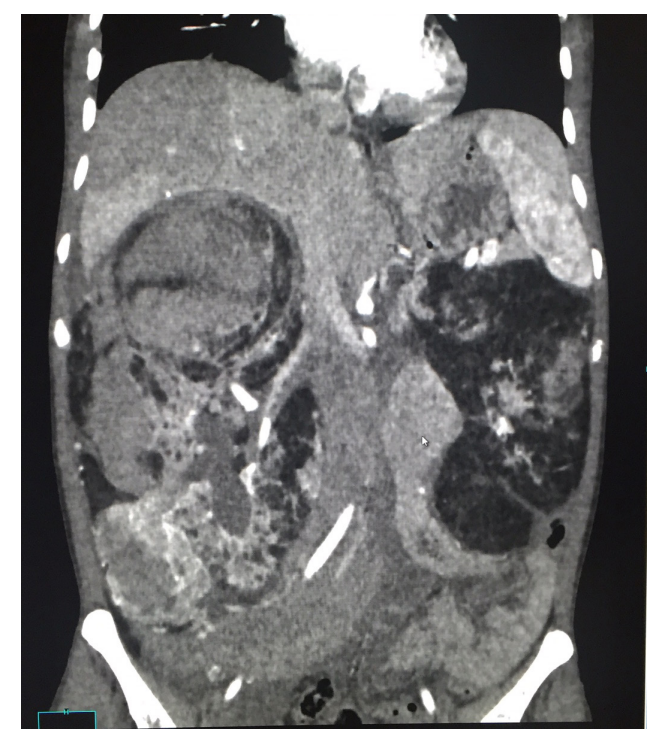

Fig.1: CT scan of the abdomen with contrast axial section shows; bilateral hugely enlarged kidneys with replacement of both kidneys by extensive fatty density masses angiomyolipomas. 
cephalosporin. Patient was daily followed clinically, biochemically and radiologically. During follow up, patient developed low grade fever which was managed by antipyretics and subsided within 3 days. At $7^{\text {th }}$ day post-admission, patient was stable and transferred for selective right renal artery embolization which was successfully done [Fig.6-9].

Patient was appointed for strict follow up program to assess general condition, results of embolization and renal function. Two months later, a part from regression of the tumor masses and hematoma, patient was unremarkably well and clinically stable. Patient was advised to consult a medical facility with kidney transplant capabilities.

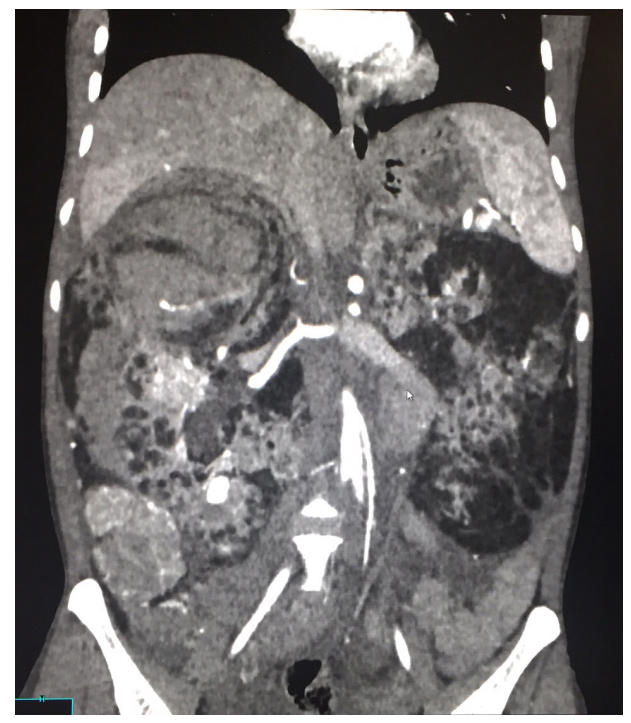

Fig.2: CT scan of the abdomen with contrast axial section shows associated large right perirenal, retroperitoneal hemorrhage, (long white arrow). A soft tissue attenuation lesion (short white arrow) in the right renal lower pole appears enhanced post contrast with multiple feeding vessels seen on CT angiography either represent soft tissue component of the angiomyolipoma but renal cell carcinoma cannot excluded since present in the context of tuberous sclerosis.

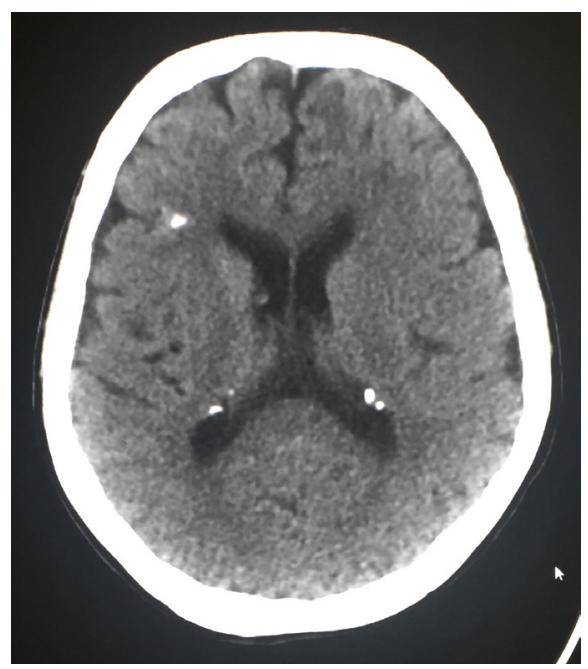

Fig.3: A CT scan, axial slice of the brain, patient with TSC shows a multiple bilateral calcified ependymal tubers with a right sided subcortical tuber.

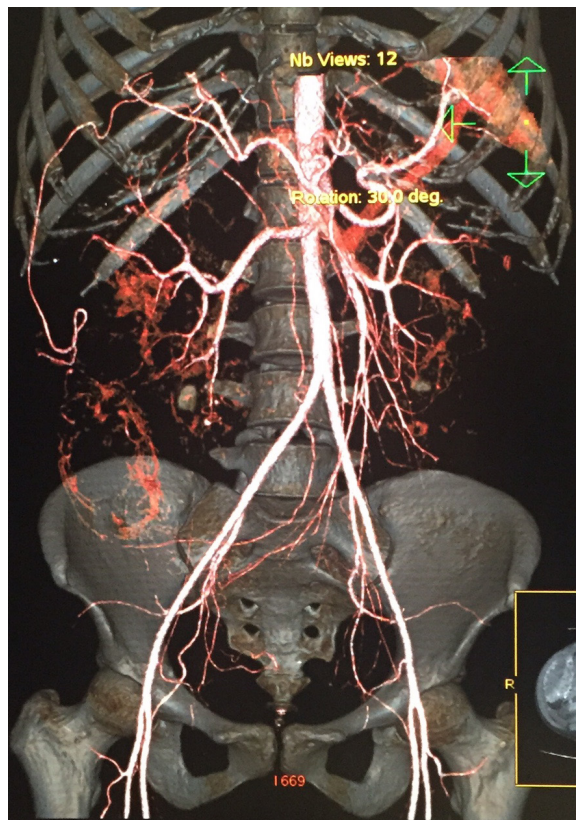

Fig.4: CT angiography revealed multiple dysplastic vessels with multiple small aneurysms largest seen at the inferior border of upper pole renal hematoma. A two large feeding vessels to the upper \& lower pole of the soft tissue enhanced component. 


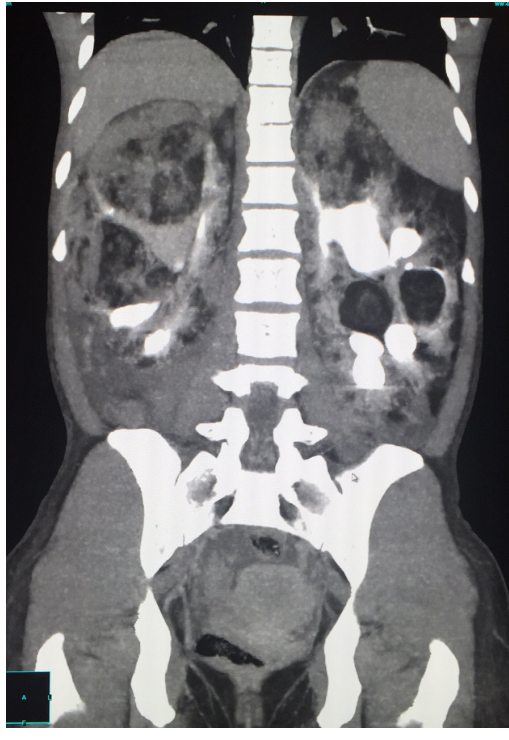

Fig. 5: MIP (maximum intensity projection) image revealed the upper pole hematoma with the largest aneurysm seen in the lower pole (arrow) which is suspected to be the cause of the hemorrhage.

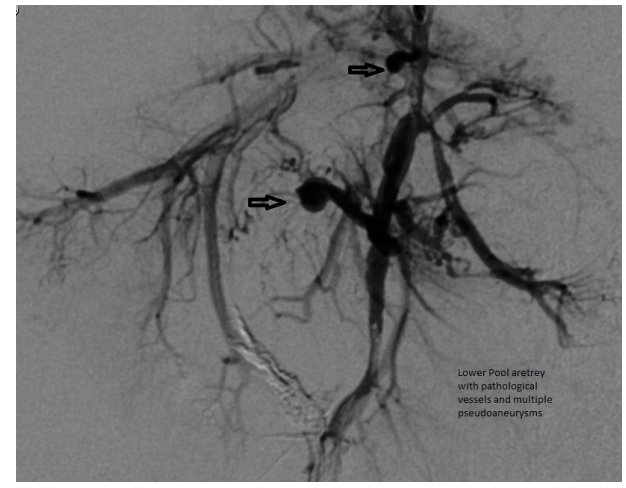

Fig.6: Angiography reveals multiple pathological vessels and pseudoaneurysems affecting lower pole artery during embolization.

\section{Discussion}

Angiomyolipoma is the commonest cause of acute spontaneous retroperitoneal bleeding. The presence of fat [confirmed on nonenhanced thin- slice CT by a value of -20 Hounsfield Units

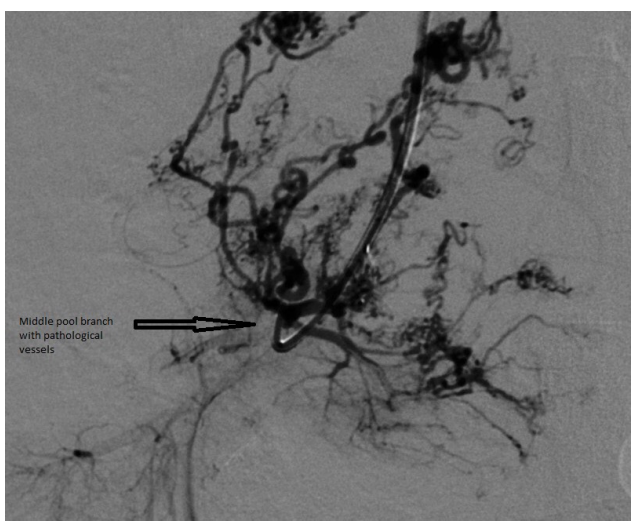

Fig.7: Angiography reveals multiple pathological vessels and pseudoaneurysems affecting middle renal artery during embolization.

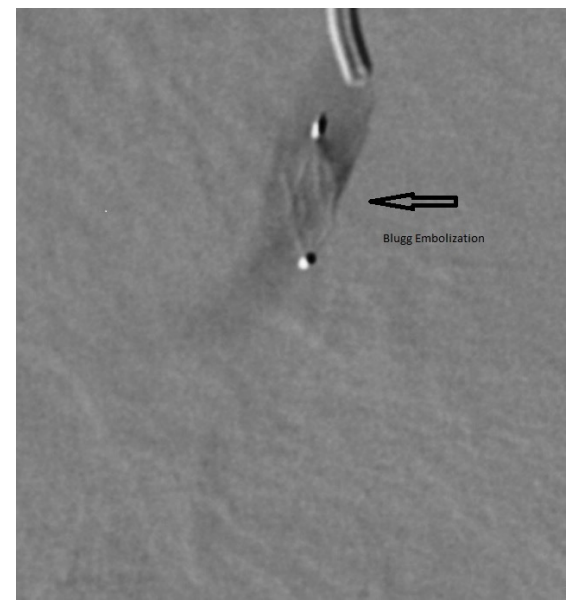

Fig.8: Embolization, using plug.

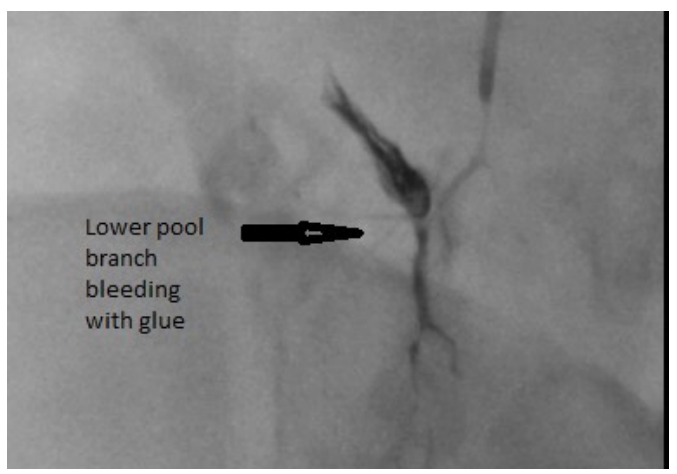

Fig.9: Embolization, using glue. 
(HU) or less] within a renal lesion is considered diagnostic $[13,14]$. Despite the radiographic stigmata of angiomyolipoma the diagnosis can be confused with, fat-containing RCC, and possibility of a fat-poor angiomyolipoma resembling an RCC $[15,16]$. Because of the nonspecific nature of these findings most patients are often treated as having a presumed RCC. However, these radiographic findings may prompt the urologist to consider a percutaneous biopsy [17]. Eble and colleagues published their experience of five patients who had angiomyolipoma with a predominant epithelioid component; this malignant epithelioid variant of angiomyolipoma that can metastasize has been further described in patients with and without TSC $[1,3,18]$.

For optimum management, treatment must be individualized. Therefore it should take into account tumor characteristics (size; number; laterality), clinical presentation (bleeding, shock) and other factors (pregnancy) [19]. Even large tumors can remain asymptomatic for long time reinforcing the concept that size represents a continuum of risk, not an absolute phenomenon [20,21]. Preservation of renal tissue remains a priority in those with TSC or multiple angiomyolipoma, particularly in patients with underlying renal insufficiency. Women of childbearing age and patients with limited access to medical facility or to emergency care should also be considered for a proactive approach [3]. A nephron-sparing approach, by either selective embolization or partial nephrectomy is clearly preferred by patients requiring intervention. Selective embolization should be considered as firstline therapy in patients with acute life-threatening hemorrhage, because in this particular situation, surgical exploration is often associated with total nephrectomy [19-21]. However, patients need extended follow-up after selective embolization, which would not be required after partial nephrectomy [3]. Ablative therapies have also been utilized for the treatment of angiomyolipoma, but follow-up remains short and the evaluation of success remains poorly defined $[22,23]$.

\section{Conclusion}

Giant, multiple, bilateral, angiomyolipoma in patient with tuberous sclerosis presented as Wunderlich syndrome is a urologic dilemma. Preservation of renal function and overall quality of life should be a priority. Selective embolization as a nephron sparing approach is the main stay of conservative management which fulfills our target. Joint decision and patient preference were considered crucial for the patient best interest. Conservative medical treatment followed by intervention versus emergency intervention (embolization; open or laparoscopic/robotic partial nephrectomy) remain the sole question to be answered in the future.

\section{References}

1. Eble JN. Angiomyolipoma of kidney. Seminars Diagnostic Pathology. 1998; 15(1):21-40.

2. Tamboli P, Ro JY, Amin MB, Ligato S, Ayala AG. Benign tumors and tumor-like lesions of the adult kidney. Part II: Benign mesenchymal and mixed neoplasms, and tumor-like lesions. Advanced Anatomy Patholology. 2000;7(1):47-66.

3. Nelson CP, Sanda MG. Contemporary diagnosis and management of renal Angiomyolipoma. J Urol. 2002;168(4 Pt 1):1315-1325.

4. Kattar MM, Grignon DJ, Eble JN, Hurley PM, Lewis PE, Sakr WE, Cher ML. Chromosomal analysis of renal angiomyolipoma by comparative genomic hybridization: evidence for clonal origin. Human Pathology. 1999;30(3):295-299.

5. Boorjian SA, Sheinin Y, Crispen PL, Lohse CM, Kwon $E D$, Leibovich BC. Hormone receptor expression in renal angiomyolipoma: clinicopathologic correlation. Urology. 2008;72(4):927-932.

6. Seyam RM, Bissada NK, Kattan SA, Mokhtar $A A$, Aslam M, Fahmy WE, et al. Changing trends 
in presentation, diagnosis and management of renal angiomyolipoma: comparison of sporadic and tuberous sclerosis complex-associated forms. Urology. 2008;72(5):1077-1082.

7. Lendvay TS, Marshall FF. The tuberous sclerosis complex and its highly variable manifestations. J Urol. 2003;169(5):1635-1642.

8. Neumann HP, Schwarzkopf G, Henske EP. Renal angiomyolipomas, cysts, and cancer in tuberous sclerosis complex. Semin Pediatric Neurol. 1998;5(4):269-275.

9. Steiner MS, Goldman SM, Fishman EK, Marshall FF. The natural history of renal angiomyolipoma. J Urol. 1993; 150(6):1782-1786.

10. Rakowski SK, Winterkorn EB, Paul E, Steele DJ, Halpern EF, Thiele EA. Renal manifestations of tuberous sclerosis complex: Incidence, prognosis, and predictive factors. Kidney Int. 2006;70(10):1777-1782.

11. Oesterling JE, Fishman EK, Goldman SM, Marshall FF. The management of renal angiomyolipoma. J Urol. 1986;135(6):11211124.

12. Zhang JQ, Fielding JR, Zou KH. Etiology of spontaneous perirenal hemorrhage: a meta-analysis. The Journal of Urology. 2002;167(4): 1593-1596.

13. Lemaitre L1, Claudon M, Dubrulle F, Mazeman E. Imaging of angiomyolipomas. Semin Ultrasound CT MR. 1997;8(2):100-114.

14. Simpfendorfer C, Herts BR, Motta-Ramirez GA, Lockwood DS, Zhou $M$, Leiber $M$, et al. Angiomyolipoma with minimal fat on MDCT: can counts of negative-attenuation pixels aid diagnosis? Am J Roentgenol. 2009 ; 192(2):438443.

15. Clark PE, Novick AC. Exophytic noninvasive growth pattern of renal angiomyolipomas: implications for nephron sparing surgery. J Urol. 2001; 165(2):513-514.
16. Cibas ES, Goss GA, Kulke MH, Demetri GD, Fletcher CD. Malignant epithelioid angiomyolipoma ('sarcoma ex angiomyolipoma') of the kidney: a case report and review of the literature. Am J Surg Pathol. 2001;25(1):121 126.

17. Lebret T1, Poulain JE, Molinie V, Herve JM, Denoux Y, Guth A, Scherrer A, Botto H. Percutaneous core biopsy for renal masses: indications, accuracy and results. J Urol. 2007;178(4 Pt 1):1 184-1 188; discussion 1188.

18. Limaiiem F, Mekni A, Chelly I, Nouira Y, Khadija B, Haovet $S$, et al. Renal epithelioid angiomyolipoma: a case report and literature review. Pathologica. 2008; 100(1):31-35.

19. Hadley DA, Bryant LJ, Ruckle HC. Conservative treatment of renal angiomyolipomas in patients with tuberous sclerosis. Clin Nephrol. 2006;65(1):22-27.

20. Pappas P, Leonardou P, Papadoukakis S, Zavos $G$, Michail S, Boletis J, et al. Urgent superselective segmental renal artery embolization in the treatment of life-threatening renal hemorrhage. Urol Int. 2006;77(1):34-41.

21. Chang YH, Wang LJ, Chuang CK, Wong YC, Wu CT, Hsieh ML. The efficacy and outcomes of urgent superselective transcatheter arterial embolization of patients with ruptured renal angiomyolipomas. J Trauma. 2007;62(6): 1487 1490.

22. Prevoo W, van den Bosch MA, Horenblas S. Radiofrequency ablation for treatment of sporadic angiomyolipoma. Urology. 2008;72(1):188-191.

23. Littrup PJ, Ahmed A, Aoun HD, Noujaim DL, Harb T, Nakat $S$, et al. CT-guided percutaneous cryotherapy of renal masses. J Vasc Interv Adiol. 2007;18(3):383-392. 